\title{
Inoperable de novo metastatic colorectal cancer with primary tumour in situ: Evaluating discordant responses to upfront systemic therapy of the primary tumours and metastatic sites and complications arising from primary tumours (experiences from an Irish Cancer Centre)
}

\author{
RUBA A. HAMED ${ }^{1}$, SAM MARKS ${ }^{1}$, HELEN MCELLIGOTT ${ }^{1}$, ROSHNI KALACHAND ${ }^{1}$, \\ HAWA IBRAHIM $^{2}$, SAID ATYANI ${ }^{3}$, GREG KORPANTY ${ }^{1}$ and NEMER OSMAN ${ }^{1}$ \\ ${ }^{1}$ Department of Oncology, Mid-Western Cancer Centre, University Hospital Limerick, \\ Limerick V94 F858; ${ }^{2}$ Palliative Department, St. Francis Hospice, Dublin 5 D05 T9K8; ${ }^{3}$ Radiology Department, \\ University Hospital Limerick, Limerick V94 F858, Ireland
}

Received March 25, 2021; Accepted November 22, 2021

DOI: $10.3892 /$ mco.2021.2472

\begin{abstract}
Systemic therapy is the mainstay of treatment for de novo metastatic colorectal cancer (mCRC). Heterogeneity between primary tumours and metastases may lead to discordant responses to systemic therapy at these sites. The aim of the present study was to examine these discrepancies and to evaluate the rates of complications arising from the primary tumour and the strategies employed to manage these complications. Electronic medical records were screened for patients eligible for data analysis between January 1st, 2014 and December 31st, 2019. All patients diagnosed with de novo mCRC with primary tumour in situ at the time of initial systemic therapy were included in data analysis. Responses in primary tumour and metastatic sites (according to the Response Evaluation Criteria In Solid Tumours v1.1), discrepancies in these responses and rates of complications arising from primary tumours were assessed along with patient, pathological or molecular factors that may be associated with these discrepant responses or primary tumour complications. A total of 50 patients were identified (median age, 62 years). Right-colon, left-colon and rectal primary tumours comprised 34,44 and $22 \%$ of CRC cases, respectively. All patients received 5-fluorouracil-based chemotherapy (either alone or in combination with oxaliplatin or irinotecan). Disease response (DR), stable disease
\end{abstract}

Correspondence to: Dr Ruba A. Hamed, Department of Oncology, Mid-Western Cancer Centre, University Hospital Limerick, St. Nessan's Road, Dooradoyle, Limerick V94 F858, Ireland E-mail: ruba.hamed@hse.ie

Key words: colon cancer, primary tumour, metastases, chemotherapy, discordant response, complication, interventions
(SD) and progressive disease (PD) were observed as the first response to systemic therapy in 24,62 and $12 \%$ of primary tumours and in 36,18 and $44 \%$ of metastatic sites, respectively. Only $36 \%$ of patients demonstrated concordant responses between the primary tumours and metastases, while the remaining $62 \%$ demonstrated discordant responses between the primary tumour and distant metastases (22\% had DR with SD; $36 \%$ had DR or SD with PD; and 4\% had PD with SD in the primary tumour and metastases, respectively). Restaging images were not available for $2 \%$ of the patients. Approximately $30 \%$ of patients developed complications from primary tumours, including bowel obstruction (6.12\%), perforation (6\%), rectal pain (6\%) and rectal bleeding (10\%). Approximately $10 \%$ of patients underwent palliative stoma creation. Additionally, $12 \%$ required palliative radiotherapy to the primary tumour (due to localized complications arising from the tumour). Discordant responses to systemic therapy between primary tumours and metastases occurred in $60 \%$ of patients with de novo mCRC (with primary tumour in situ at the time of first systemic therapy). The observations of the present study have potential implications for molecular tissue analysis to help guide systemic therapy. Tissue from metastatic sites may be preferable to confirm biomarker status in mCRC based on this study.

\section{Introduction}

According to global cancer statistics, colorectal cancer (CRC) is the third most common type of cancer diagnosed worldwide, accounting for just over 10\% of all diagnosed cancers. This is surpassed only by cancers of the lung and breast (the latter in women). CRC is the second leading cause of cancer-related mortality, accounting for just over $9 \%$ of cancer-related deaths (1). Approximately $20 \%$ of patients with CRC demonstrate metastases at initial diagnosis (metastatic CRC; mCRC), whether detected on imaging or confirmed during biopsy, 
with up to $80 \%$ of such patients deemed unresectable at initial diagnosis $(2,3)$.

Systemic therapy is the mainstay of treatment for patients with inoperable CRC. Localized therapy in the palliative setting (namely surgical resection and irradiation of the primary tumour) is commonly limited to patients suffering from primary tumour complications. These can include bowel obstruction, perforation, localized pain and bleeding from the tumour $(4,5)$.

Chemotherapeutic agents typically employed in mCRC consist of the antimetabolite 5-fluorouracil (5FU) $(6,7)$, the pyrimidine analogue capecitabine (8), the topoisomerase inhibitor irinotecan (9) and the alkylating agent oxaliplatin (10). EGFR-targeting monoclonal antibodies include cetuximab (11) and panitumumab (12) for confirmed KRAS/NRAS wild-type tumours and VEGF-targeting bevacizumab (13) and ramucirumab (14), the latter typically in combination with chemotherapy using the FOLFIRI regimen (15).

Oxaliplatin-containing regimens, such as FOLFOX $(16,17)$ or XELOX $(18,19)$ and irinotecan-containing regimens, such as FOLFIRI (20-22) and XELIRI (23-25), have both been established equally effective in terms of progression-free and overall survival as first-line palliative systemic therapy in mCRC (26). Oxaliplatin-containing regimens may be preferred over irinotecan-based regimens as first-line therapy in $\mathrm{mCRC}$ due to their slightly more favourable median overall survival and toxicity profiles $(21,27,28)$, including in elderly patients (29).

This may vary in patients for whom either oxaliplatin or irinotecan are contraindicated as first-line therapy due to their varying toxicity profiles. In patients deemed unsuitable for additional oxaliplatin and irinotecan with 5FU or capecitabine (such as patients of advanced age, with co-morbidities or poor performance status), single-agent 5FU or capecitabine may be preferred. Such single-agent 5FU regimens include the Roswell Park $(30,31)$ and QUASAR $(32,33)$ regimens and capecitabine $(34,35)$ in either the adjuvant $(36)$ or palliative (37) setting.

Combined nucleic acid analogue/thymidine phosphorylase inhibitor TAS-102 (tipiracil hydrochloride) (38) and the multikinase inhibitor regorafenib (39) are typically reserved for patients in whom 5FU-based chemotherapy in combination with oxaliplatin or irinotecan has failed (or if the patient is deemed clinically unsuitable to receive these treatments). Depending on the patient, irinotecan- or oxaliplatin-based chemotherapy may be rechallenged in the palliative setting if a significant interval has elapsed since completing a previous course of treatment, provided cumulative toxicity allows for this approach $(40,41)$.

The targeted tyrosine kinase inhibitors encorafenib and binimetinib may be considered in BRAF V600E mutant tumours in combination with other systemic therapies (42). Immune checkpoint inhibitors are reserved for microsatellite instability-high (MSI-H) or deficient mismatch repair (dMMR) tumours (43); these include the monoclonal antibody inhibitors nivolumab $(44,45)$ and pembrolizumab (46), which inhibit programmed death receptor 1, and ipilimumab (47), which inhibits cytotoxic T-lymphocyte-associated protein 4.

Tumour heterogeneity exists in mCRC, whether within the primary tumour (intra-tumoural heterogeneity) or between the primary and metastatic tumours (inter-tumoural heterogeneity) (48-50). Intra- or inter-tumoural heterogeneity has been implicated in the mechanisms underlying resistance to systemic therapy (51). Tumour heterogeneity in mCRC can vary during the course of the disease (52).

Inter-tumoural heterogeneity accounts for identifiable discordances in scientifically validated tests of advanced CRC. These discordances may include differentiation of adenocarcinoma $(53,54)$, in which cancer stem cells play a role $(55)$, mutation status (56-59), including KRAS/NRAS (60-62) and BRAF $(63,64)$ status, MSI status $(65)$ and dMMR status $(66,67)$. This may lead to discordances in biomarker profiles between the primary tumour and metastases. Inter-tumoural heterogeneity appears to be more prevalent in mCRC with certain pathological and molecular features, such as confirmed MSI $(68,69)$.

Among diagnosed CRCs, 30-40\% of carry a pathogenic somatic KRAS mutation (70), 10\% carry a NRAS mutation (71) and $10 \%$ carry a BRAF mutation (72). dMMR is identified in $10-20 \%$ (73-75) and MSI is identified in 10-20\% of diagnosed colon cancers $(76,77)$. Approximately $3 \%$ of colon cancers arise from germline mutations leading to MSI (78), a condition known as Lynch syndrome or hereditary non-polyposis CRC. Approximately $1 \%$ of cases result from germline defects in the $\alpha$-fetoprotein gene (79), a condition known as familial adenomatous polyposis. Hypermethylation of the MLH1 gene promoter occurring in tumours with the $\mathrm{CpG}$ island methylator phenotype appears to be the predominant somatic mechanism of action of MSI-H in colorectal tumours (80).

Discordant responses between the primary tumour and metastatic sites in mCRC may arise from this underlying heterogeneity between tumour sites. Tumour cells at the metastatic sites may harbour clones that have gained (or lost) mutations advantageous to their survival compared to those residing at the primary site, or vice versa $(81,82)$. These molecular discrepancies in $\mathrm{mCRC}$ are not yet fully understood; clonal evolution, cancer stem cells and 'The Big Bang' model have all been hypothesized to play a role (83-85).

The incidence of these biomarker discordances in mCRC varies depending on the resources consulted. Part of the literature, including meta-analysis studies, suggests that the rate of biomarker concordance is high between primary tumours and metastases in mCRC $(86,87)$. These studies further suggest that tissues from either the primary tumour or metastatic site are sufficient for confirming the biomarker status of mCRC to help guide the systemic therapy approach (88). However, more recent studies suggest that the rate of these discordances increases if next-generation sequencing is used $(89,90)$. There is high concordance $(>90 \%)$ between immunohistochemical analysis and molecular testing of dMMR (91).

The rates of molecular discordances between the primary tumour and metastatic sites in mCRC may be as high as $10-15 \%$, depending on the study $(86,92)$. The rate of discrepancies in MSI or MMR status tends to be low $(<5 \%)$ upon comparison $(93,94)$. The expression of other specific biomarkers, such as programmed death ligand 1 (PD-L1), may vary more markedly between primary tumour and metastatic sites in up to one-third of patients (95).

Evaluating molecular characteristics between primary and metastatic tumours separately in a single patient with mCRC 
can demonstrate variable biological behaviour and response to systemic therapy due to these identified subclones (96). Non-genetic factors, such as post-translational modification, epigenetics and the tumour microenvironment, also contribute to this phenomenon. Comparing such predictive or prognostic molecular signatures between the primary and metastatic tumours in mCRC has yielded different results. For example, mutant KRAS status exhibits concordance between the primary tumour and distant organ metastases in up to $90 \%$ of patients with mCRC (97). Conversely, comparisons between the primary tumour and lymph node metastases demonstrate lower concordance rates with a KRAS mutant status of $\sim 37 \%$ (98).

The role of pre-emptive localized therapies in patients with relatively asymptomatic primary tumours remains controversial and has demonstrated an inconsistent clinical benefit (99-101). Radiation to rectal and rectosigmoid cancer primary tumours has been associated with a reduced risk of death in one retrospective study (102). Previous findings have demonstrated no additional benefit, reduced risk of complications or death when radiation treatment is administered before systemic therapy (103), while other findings suggest that prior resection of the colorectal primary in $\mathrm{mCRC}$ offers benefit in selected patients (104). However, this should not be routinely considered in asymptomatic patients, as it offers no additional benefit (105), taking into account the currently available systemic therapies (106).

\section{Materials and methods}

Study design. A retrospective review of patients was conducted using ARIA v15.6 software (https://www.varian.com/; supplied by Varian Medical Systems). The terms 'colon cancer' and 'rectal cancer' were utilized to narrow the search and identify patients suitable for inclusion in the study. Patient records were assessed between January 1st, 2014 and December 31st, 2019. Any patients initiated on up-front systemic therapy prior to January 1st, 2014, or beyond December 31st, 2019 , were excluded from the study. Data events (radiological progression and overall survival) were not recorded beyond December 31st, 2019.

Ethics approval was obtained from the local hospital Medical Research Ethics Committee prior to data collection (REC Ref: 113/2020). Patient data were anonymized during data collection and analysis. Informed consent (written or oral) was not required, since this was a retrospective chart review (as outlined per Health Research Consent Declaration Committee Guidelines, Ireland). All data collection procedures followed the General Data Protection Regulation and the Data Protection Act, 2018.

Patient characteristics. The analysis included patients with a radiologically and pathologically confirmed diagnosis of metastatic de novo mCRC, with the primary tumour in situ treated with up-front palliative systemic therapy. Non-curative status was confirmed through multidisciplinary meeting discussion (in applicable cases requiring discussion with surgical specialists based on imaging findings). Patients considered to have operable/potentially curable mCRC at initial diagnosis per multidisciplinary meeting discussion were excluded from the analysis. Patients with a prior history of early-stage CRC treated with radical management strategies (including surgery or high-dose radiotherapy) were excluded. Patients diagnosed with de novo $\mathrm{mCRC}$ requiring up-front localized management strategies for primary tumours (radiotherapy, endoscopy or surgery) prior to palliative systemic therapy were excluded.

Mutation status and response to therapy. KRAS, NRAS and BRAF status were confirmed through next-generation sequencing CRC mutation panel test (107). MSI and MMR status were confirmed using a multiplex PCR approach followed by DNA fragment analysis and immunohistochemistry (using BenchMarckULTRA IHC/ISH by Roche Diagnostics).

The responses of primary tumours and metastases to up-front systemic chemotherapy were observed separately and discordant responses to therapy were documented based on routine interval radiological assessments. Molecular characteristics possibly associated with these discordant responses were also analysed and the incidence of complications from the primary tumours and subsequent interventions were evaluated.

Factors including patient age, sex, primary tumour location, molecular panel status and interval of response to first-line systemic therapy were recorded. Responses to systemic therapy in primary tumour and metastatic sites were recorded separately using Response Evaluation Criteria In Solid Tumours, v1.1 (108). Furthermore, the incidence of complications, types of complications arising from primary tumours and subsequent management strategies for such complications were also recorded, whether this involved conservative management (such as endoscopy, surgery, or radiotherapy, or a combination of these interventions).

Study endpoints. Primary endpoints included documented response rates to first-line up-front chemotherapy (in both primary and metastatic sites) and the rates of discordance between these responses. Primary endpoints also included evaluation of molecular and pathological factors that may be associated with the discordant radiological responses. Secondary endpoints included documenting the rate of complications arising from the primary tumour (during up-front palliative systemic therapy), the types of complications encountered and the management strategies employed.

Statistical analysis. Non-parametric tests were used to compare groups, investigate the statistical significance of the associations and analyse survival (McNamara, Friedman's and Kaplan-Meier analyses). $\mathrm{P}<0.05$ was considered to indicate statistically significant differences.

\section{Results}

Characteristics of primary and metastatic tumours. A total of 50 patients were identified and included in the analysis (median age, 62 years; interquartile range, 55-69 years). A total of 30 patients $(60 \%)$ were male. Primary tumours confined to the right colon (including the caecum, ascending and transverse colon), left colon (including the descending and sigmoid colon) and rectum were observed in $34 \%(n=17), 44 \%(n=22)$ and $22 \%(n=11)$ of the patients, respectively (Table I). 
Table I. Patient, tumour and molecular tissue characteristics with associated treatment modalities employed $(n=50)$.

\begin{tabular}{|c|c|}
\hline Characteristics & No. $(\%)$ \\
\hline \multicolumn{2}{|l|}{ Demographics } \\
\hline Male sex & $30(60)$ \\
\hline Female sex & $20(40)$ \\
\hline Age (years), median (IQR) & $62(55-69)$ \\
\hline \multicolumn{2}{|l|}{ Location of primary tumour } \\
\hline Right colon & $17(34)$ \\
\hline Left colon & $33(66)$ \\
\hline \multicolumn{2}{|l|}{ Sites of metastasis } \\
\hline Liver & $44(88)$ \\
\hline Lung & $20(40)$ \\
\hline Peritoneum & $10(20)$ \\
\hline Lymph nodes & $11(22)$ \\
\hline Other/bone & $1(2)$ \\
\hline \multicolumn{2}{|l|}{ Mutations } \\
\hline None & $19(38)$ \\
\hline KRAS & $24(48)$ \\
\hline NRAS & $2(4)$ \\
\hline BRAF & $2(4)$ \\
\hline Microsatellite instability & $1(2)$ \\
\hline NA/sample not sufficient for test & $5(10)$ \\
\hline \multicolumn{2}{|l|}{ Chemotherapy } \\
\hline 5FU/oxaliplatin (FOLFOX) & $28(56)$ \\
\hline Median number of cycles (IQR) & $8.5(4-12)$ \\
\hline 5FU/irinotecan (FOLFIRI) & $17(34)$ \\
\hline Median number of cycles (IQR) & $9(4-12)$ \\
\hline Capecitabine/irinotecan (XELIRI) & $3(6)$ \\
\hline Median number of cycles (IQR) & $3(3-6)$ \\
\hline Single-agent 5FU & $1(2)$ \\
\hline Median number of cycles & 30 weekly cycles \\
\hline 5FU/oxaliplatin (FLOX) & $1(2)$ \\
\hline $\begin{array}{l}\text { Concurrent anti-VEGF antibody } \\
\text { (bevacizumab) }\end{array}$ & $9(18)$ \\
\hline $\begin{array}{l}\text { Concurrent anti-EGFR-antibody } \\
\text { (cetuximab/panitumumab) }\end{array}$ & $12(24)$ \\
\hline
\end{tabular}

IQR, interquartile range; 5FU, 5-fluorouracil.

The most common site of metastasis at diagnosis of mCRC was the liver $(n=44,88 \%)$, followed by the lung $(n=20,40 \%)$ and peritoneum $(n=10,20 \%)$. Only 1 patient had bone metastasis. In $18(36 \%)$ and $2(4 \%)$ patients, the liver and lung were the only sites of metastasis, respectively. Finally, 10 patients (20\%) had both liver and lung metastases at diagnosis (Table I).

Metastasis involving one, two and three or more organ sites were present in 23 (46\%), 20 (40\%) and 7 (14\%) patients, respectively, at the time of diagnosis of non-curative mCRC. KRAS, NRAS and BRAF were found to be mutated in 24 (48\%), 2 (4\%) and 2 (4\%) cases, respectively. Furthermore, 2 patients $(4 \%)$ had synchronous KRAS and BRAF mutations. Only 1 patient (2\%) harboured KRAS mutation with MSI, and 5 patients $(10 \%)$ could not have their mutation panels performed due to insufficient tissue available for diagnosis (Table I).

Treatment and response. All patients received 5FU-based chemotherapy. A total of 28 patients $(56 \%)$ received concurrent oxaliplatin (FOLFOX regimen) and 17 (34\%) received concurrent irinotecan (FOLFIRI regimen) as first-line treatment, with an observed median treatment duration of 17 and 19 weeks, respectively. Furthermore, 3 patients (6\%) received concurrent capecitabine with irinotecan (XELIRI regimen) with a median treatment duration of 6 weeks, while 1 patient received single-agent 5FU (QUASAR regimen) for up to 30 weeks (Table I).

VEGR-targeted monoclonal antibody therapy (bevacizumab) was used in 9 patients (18\%), whereas EGFR-targeted monoclonal antibody therapy (cetuximab and panitumumab) was used in 12 patients (24\%), concurrently with first-line chemotherapy (Table I). Over half of the patients had received one line of systemic therapy for mCRC $(n=27,54 \%), 11(22 \%)$ had received up to two lines of chemotherapy, and 11 patients (22\%) had received three or more lines of chemotherapy (by data cut-off).

Radiological assessment of response to palliative systemic therapy demonstrated significant discordant responses between the primary tumour and metastatic sites. Primary tumours demonstrated disease response (DR), stable disease (SD) and progressive disease (PD) in 24, 62 and $12 \%$ of patients on first-line palliative systemic therapy, respectively.

By contrast, metastatic lesions demonstrated DR, SD and PD on first-line chemotherapy in 36, 18 and $44 \%$ of patients, respectively (Table II). Only 18 (36\%) of the patients demonstrated concordant responses in both the primary tumour and metastatic sites on first-line palliative systemic therapy. A total of 11 patients $(22 \%)$ demonstrated discordant responses consisting of SD with DR, $n=2(4 \%)$ had PD with SD, and $n=18$ (36\%) had either DR or SD with PD in the primary tumour and metastatic sites respectively (Table III). Discordant responses between the primary tumour and metastatic sites did not vary significantly according to the KRAS/NRAS/BRAF mutant $(\mathrm{P}>0.05)$.

A total of 15 patients (30\%) developed complications arising from the primary tumours during the course of up-front first-line systemic therapy. As regards complications arising from the primary tumour requiring intervention, 6 patients $(12 \%)$ developed bowel obstruction and 3 patients (6\%) developed bowel perforation; an additional 8 patients (16\%) developed either pain or bleeding from the primary tumour, necessitating local intervention. Only 1 patient developed a primary tumour-associated abscess requiring drainage and surgical resection. An outline of complications from the primary tumour and the management strategies employed is outlined in Table IV.

Of the 50 patients, 38 (76\%) did not develop any complications from their primary tumour requiring intervention while receiving palliative systemic therapy or by the time of data cut-off. A total of 3 patients $(6 \%)$ initially deemed inoperable/non-curable at diagnosis ultimately proceeded to undergo surgery with curative intent with resection of the primary tumour, metastasectomy, or other local therapies (e.g., 
Table II. Radiological assessment after first-line chemotherapy.

\begin{tabular}{lcr}
\hline Type of response & Primary sites, $\mathrm{n}(\%)$ & Distant metastatic sites, $\mathrm{n}(\%)$ \\
\hline Disease progression & $6(12)$ & $22(44)$ \\
Stable disease & $31(62)$ & $9(18)$ \\
Disease response & $11(22)$ & $18(36)$
\end{tabular}

Table III. Difference in response between primary and metastatic sites among patients.

\begin{tabular}{|c|c|c|c|c|}
\hline Type of response & Primary site & Metastatic sites & $\%$ & Total $\%$ \\
\hline \multirow[t]{3}{*}{ Concordant response } & $\mathrm{PD}$ & $\mathrm{PD}$ & 8 & 36 \\
\hline & $\mathrm{SD}$ & $\mathrm{SD}$ & 12 & \\
\hline & DR & DR & 16 & \\
\hline \multirow[t]{2}{*}{ Discordant response with SD or DR } & $\mathrm{SD}$ & DR & 20 & 22 \\
\hline & DR & SD & 2 & \\
\hline \multirow[t]{3}{*}{ Discordant response with PD at one site } & DR & $\mathrm{PD}$ & 6 & 40 \\
\hline & $\mathrm{SD}$ & $\mathrm{PD}$ & 30 & \\
\hline & PD & SD & 4 & \\
\hline
\end{tabular}

$\mathrm{PD}$, progressive disease; $\mathrm{DR}$, disease response; $\mathrm{SD}$, stable disease.

Table IV. Complications arising from primary colorectal tumour and localized interventions employed.

\begin{tabular}{ll}
\hline Complications of primary tumour sites & No. $(\%)$ \\
\hline Type of complication & \\
Obstruction & $6(12)$ \\
Obstruction and perforation & $3(6)$ \\
Abscess & $1(2)$ \\
Pain & $3(6)$ \\
Bleeding & $5(10)$ \\
Type of intervention & $3(6)$ \\
Curative surgical resection of primary/ \\
metastatic site (metastasectomy) \\
Palliative radiotherapy only \\
$\begin{array}{l}\text { Palliative stoma creation (colostomy/ } \\
\text { ileostomy) }\end{array}$ \\
\begin{tabular}{l} 
Stoma creation with radiotherapy \\
\hline
\end{tabular}
\end{tabular}

radiation) to metastatic sites. These management strategies were undertaken considering marked radiological treatment response following repeat multidisciplinary team meeting discussions.

A total of 5 patients (10\%) required emergent defunctioning stoma creation (colostomy or ileostomy) for bowel obstruction, or perforation. A total of 6 patients (12\%) required local radiotherapy for primary tumour in situ, most often for rectal bleeding or localized pain. Only 1 patient underwent both stoma creation and local irradiation (Table IV).
Left-sided primary tumours were associated with a significantly higher rate of complications requiring local intervention compared with right-sided tumours $(\mathrm{P}<0.001)$, with complications arising in 17 (34\%) and 9 (18\%) cases, respectively. The median overall survival was 14.0 months (95\% CI: 10.0-36.0; Fig. 1). At the time of data cut-off (December 31st, 2019), 7 patients (14\%) remained alive, 3 of whom were receiving their third line of systemic therapy, 2 were receiving their fourth line and 2 were off treatment (undergoing active clinical follow-up with radiological surveillance).

\section{Discussion}

The present study demonstrated that up-front palliative systemic therapy can effectively control primary tumours in patients with de novo $\mathrm{mCRC}$ with primary tumours in situ that are deemed inoperable/non-curable at initial diagnosis. However, while up-front systemic therapy with palliative intent is predominantly effective in mCRC with primary tumour in situ, $24 \%$ of patients in our study required localized intervention due to complications arising from the primary tumour (on first-line systemic therapy).

Other studies have demonstrated a reduced risk of primary tumour-related complications and the need for emergent surgical intervention with up-front localized interventions prior to undertaking palliative systemic therapy $(3,101)$. Most international guidelines currently recommend combination chemotherapy as the initial treatment for unresectable mCRC with primary in situ $(109,110)$. Local interventions for primary tumours are typically reserved for when complications arise from the primary tumour after palliative systemic therapy 


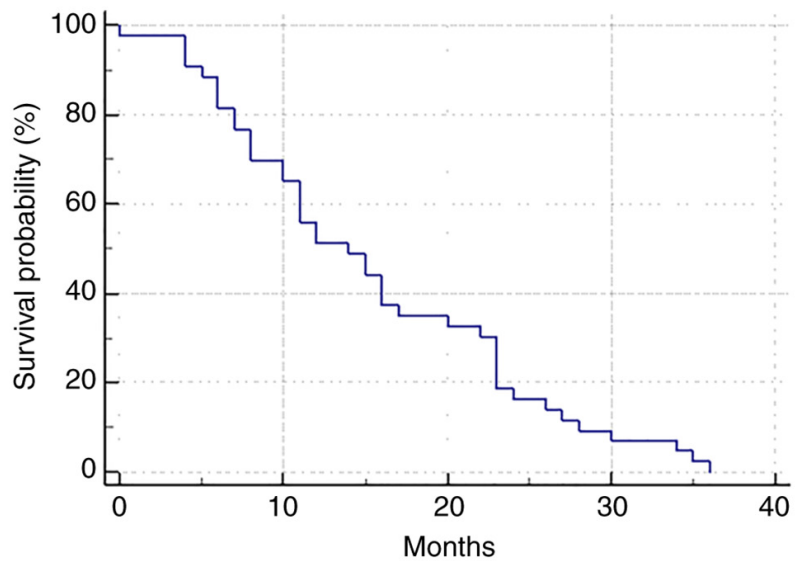

Figure 1. Kaplan Meier curve demonstrating a median overall survival of 14 months (95\% CI: 10.0-36.0).

has already been employed (including bowel obstruction, perforation, significant pain, or bleeding from the primary tumour) (111,112).

In the present study, higher rates of radiological response were observed in primary tumours compared with metastatic tumour sites. Nonetheless, the rate of complications arising from the primary tumour requiring intervention during systemic therapy remained high (up to $25 \%$ of cases in this patient cohort).

In a retrospective study involving 233 patients with mCRC receiving combined chemotherapy with or without bevacizumab as up-front first-line systemic therapy (113), only $7 \%$ of these patients required emergent surgical intervention, and $4 \%$ required emergent non-surgical intervention (radiation and endoscopic stenting) while on systemic therapy. On the other hand, the remaining 213 patients $(89 \%)$ never required local intervention for their primary tumour. Another study observed that, among 83 asymptomatic patients with non-curable mCRC treated with first-line chemotherapy (114), only 5\% required surgery, while $4 \%$ required colonic stenting to manage complications arising from the primary tumour.

Conversely, other studies support prophylactic surgical resection of the primary tumours in non-curable mCRC before undertaking palliative-intent systemic therapy to reduce the future risk of primary tumour complications $(2,3,101)$. One meta-analysis reviewed eight retrospective studies including 1,062 patients (101) and observed that up-front primary tumour resection was associated with reduced rates of primary tumour-associated complications requiring emergent localized intervention and increased overall survival rate. This was compared to patients receiving up-front palliative systemic therapy alone, who were 7.3 times more likely to suffer acute complications requiring localized interventions while on palliative systemic therapy.

Current randomized control trials, such as the SYNCHRONOUS trial (ISRCTN30964555) and the iPACS study (JCOC1007) are comparing up-front palliative chemotherapy alone with up-front primary tumour resection followed by palliative chemotherapy in patients with non-curative mCRC with asymptomatic primary tumours at diagnosis $(115,116)$.
Multiple studies have observed conflicting results when addressing the concordance rates of KRAS, NRAS and BRAF mutation status between the primary colorectal tumour and metastatic sites. While some results showed no significant difference in mutation status (namely KRAS) between the primary tumours and corresponding metastases, others showed discordant results in $4-32 \%$ of the patients (16). One study including 305 patients demonstrated a high concordance rate of KRAS mutation status (96.4\%) between primary colorectal tumours and corresponding liver metastases $(23,24)$. Mutation status discordance rates of $\leq 25 \%$ between the primary tumour and the lymph node metastases were also observed (117).

There were certain limitations to the present study. Certain patient variables (such as past medical history, ethnicity, dietary history, smoking history, and whether patients did or did not attend a colorectal screening program) were not assessed as part of the analysis, as they were considered to be outside the scope of this study, and due to relatively small patient number. This is further taking into account the small number of patients accrued in this data analysis, which limits the validity of statistical associations observed. Further research (ideally a meta-analysis) is required to assess and, ultimately, validate the associations observed in this study.

In the present study, statistically appreciable rates of discordant radiological responses to up-front palliative systemic therapy were observed between the primary tumour and metastatic tumour sites in patients with inoperable/non-curative de novo mCRC (in up to $60 \%$ of our patient cohort). Approximately one-third of the patients demonstrating radiological control of the primary tumour otherwise demonstrated progression at metastatic sites while on first-line up-front single-modality palliative systemic therapy at the first interval restaging imaging.

This has implications for molecular analyses of the tissues obtained from patients diagnosed with mCRC. Our analysis suggests that standard molecular panels performed in $\mathrm{mCRC}$ (including KRAS, NRAS and BRAF status with MMR and MSI analyses) should preferentially be performed on tissue from metastatic sites rather than on tissue from the primary tumour.

Up-front localized management strategies, such as palliative radiation to the primary tumour, surgical interventions (including stoma formation) and endoscopic procedures (such as colonic stenting) should be considered in certain patients with inoperable mCRC.

\section{Acknowledgements}

Not applicable.

\section{Funding}

No funding was received.

\section{Availability of data and materials}

The datasets used and/or analysed during the current study are available from the corresponding author on reasonable request. 


\section{Authors' contributions}

RAH: Conception and design of the study, data collection and analysis, writing and drafting the manuscript. SM: Participation in manuscript writing and collection of references. HM and HI: Critical revision of the manuscript for important intellectual content. SA: Assessment of radiological responses according to RECIST criteria. RK and GK: Critical revision and editing of the manuscript. NO: Conception and design of the study, manuscript editing and critically revising the work for important intellectual content. All authors have read and approved the final manuscript. All authors agree to be accountable for all aspects of the work in ensuring that questions related to the accuracy or integrity of any part of the work are appropriately investigated and resolved.

\section{Ethics approval and consent to participate}

Ethics approval was obtained from the local hospital Medical Research Ethics Committee prior to data collection (REC Ref:113/2020). Patient data were anonymized during data collection and analysis. Informed consent (written or oral) was not required, since this was a retrospective chart review (as outlined per Health Research Consent Declaration Committee Guidelines, Ireland). All data collection procedures followed the General Data Protection Regulation and the Data Protection Act, 2018.

\section{Patient consent for publication}

Not applicable.

\section{Competing interests}

The authors declare that they have no competing interests.

\section{References}

1. Bray F, Ferlay J, Soerjomatarum I, Siegal RL, Torre LA and Jemal A: Global cancer statistics 2018: GLOBOCAN estimates of incidence and mortality worldwide for 36 cancers in 185 countries. CA Cancer J Clin 68: 394-424, 2018.

2. Clancy C, Burke JP, Barry M, Kalady MF and Calvin Coffey J: A meta-analysis to determine the effect of primary tumour resection for stage IV colorectal cancer with unresectable metastases on patient survival. Annals Surg Oncol 21: 3900-3908, 2014.

3. Kim CW, Baek JH, Choi GS, Yu CS, Kang SB, Park WC, Lee $\mathrm{BH}, \mathrm{Kim} \mathrm{HR}$, Oh JH, Kim JH, et al: The role of primary tumour resection in the colorectal cancer patients with asymptomatic, synchronous unresectable metastasis: Study protocol for a randomized control trial. Trials 17: 34, 2016

4. Tan WJ, Patil S, Guillem JG, Paty PB, Weiser MR, Nash GM, Smith JJ, Pappou EP, Wei IH and Garcia-Aguilar J: Primary Tumour-related complications and salvage outcomes in patients with metastatic rectal cancer and an untreated primary tumour. Dis Colon Rectum 64: 45-52, 2021.

5. de Mestier L, Manceau G, Neuzillet C, Bachet JB, Spano JP, Kianmanesh R, Vaillant JC, Bouché O, Hannoun L and Karoui M: Primary tumour resection in colorectal cancer with unresectable synchronous metastases: A review. World J Gastrointest Oncol 6: 156-169, 2014.

6. Machover D: A comprehensive review of 5-fluorouracil and leucovorin in patients with metastatic colorectal carcinoma. Cancer 8: 1179-1187, 1997.

7. Kurkjian C and Kummar S: Advances in the treatment of metastatic colorectal cancer. Am J Ther 16: 412-420, 2009.
8. Leicher LW, de Graaf JC, Coers W, Tascilar M and de Groot JWB: Tolerability of capecitabine monotherapy in metastatic colorectal cancer: A real-world study. Drugs R D 17: 117-124, 2017.

9. Fujita K, Kubota Y, Ishida H and Sasaki Y: Irinotecan, a key chemotherapeutic drug for metastatic colorectal cancer. World J Gastroenterol 21: 12234-12248, 2015.

10. Comella P, Casaretti R, Sandomenico C, Avallone A and Franco L: Role of oxaliplatin in the treatment of colorectal cancer. Ther Clin Risk Manag 5: 229-238, 2009.

11. Fornasier G, Francescon S and Baldo P: An update of efficacy and safety of cetuximab in metastatic colorectal cancer: A narrative review. Adv Ther 35: 1497-1509, 2018.

12. Battagin F, Puccini A, Djaballah SA and Lenz HJ: The impact of panitumumab treatment on survival and quality of life in patients with RAS wild-type metastatic colorectal cancer. Cancer Manag Res 11: 5911-5924, 2019.

13. Rosen LS, Jacobs IA and Burkes RL: Bevacizumab in colorectal cancer: Current role in treatment and the potential of biosmiliars. Target Oncol 12: 599-610, 2017.

14. Verdaguer H, Tebernero J and Macarulla T: Ramucirumab in metastatic colorectal cancer: Evidence to date and place in therapy. Ther Adv Med Oncol 8: 230-242, 2016.

15. Yoshihiro T,KusabaH,Makiyama A,KobayashiK, Uenomachi M, Ito M, Doi Y, Mitsugi K, Aikawa T, Takayoshi K, et al: Efficacy and safety of ramucirumab plus modified FOLFIRI for metastatic colorectal cancer. Int J Clin Oncol 24: 508-515, 2019.

16. Braun MS, Adab F, Bradley C, McAdam K, Thomas G, Wadd NJ, Rea D, Philips R, Twelves C, Bozzino J, et al: Modified de Gramont with oxaliplatin in the first-line treatment of advanced colorectal cancer. Br J Cancer 89: 1155-1158, 2003.

17. de Gramont A, Figer A, Seymour M, Homerin M, Hmissi A, Cassidy J, Boni C, Cortes-Funes H, Cervantes A, Freyer G, et al: Leucovorin and fluorouracil with or without oxaliplatin as first-line treatment in advanced colorectal cancer. J Clin Oncol 18: 2938-2947, 2000.

18. Guo Y, Xiong BH, Zhang T, Cheng Y and Ma L: XELOX vs. FOLFOX in metastatic colorectal cancer: An updated meta-analysis. Cancer Invest 34: 94-104, 2016.

19. Cassidy J, Clarke S, Díaz-Rubio E, Scheithauer W, Figer A, Wong R, Koski S, Rittweger K, Gilberg F and Saltz L: XELOX vs FOLFOX-4 as first-line therapy for metastatic colorectal cancer: NO16966 updated results. Br J Cancer 105: 58-64, 2011.

20. Saltz LB, Douillard JY, Pirotta N, Alakl M, Gruia G, Awad L, Elfring GL, Locker PK and Miller LL: Irinotecan plus fluorouracil/leucovorin for metastatic colorectal cancer: A new survival standard. Oncologist 6: 81-91, 2001.

21. Tournigard C, André T, Achille E, Lledo G, Flesh M, Mery-Mignard D, Quinaux E, Couteau C, Buyse M, Ganem G, et al: FOLFIRI followed by FOLFOX6 or the reverse sequence in advanced colorectal cancer: A randomized GERCOR study. J Clin Oncol 22: 229-237, 2004.

22. Heinemann V, von Weikersthal LF, Decker T, Kiani A, Vehling-Kaiser U, Al-Batran SE, Heintges T, Lerchenmüller C, Kahl C, Seipelt G, et al: FOLFIRI plus cetuximab versus FOLFIRI plus bevacizumab as first-line treatment for patients with metastatic colorectal cancer FIRE-3): A randomised, open-label, phase 3 trial. Lancet Oncol 15: 1065-1075, 2014.

23. Price TJ: Modified XELIRI (capecitabine plus irinotecan) for metastatic colorectal cancer. Lancet Oncol 19: 587-589, 2018.

24. Yaffee P, Osipov A, Tan C, Tuli R and Hendifar A: Review of systemic therapies for locally advanced and metastatic rectal cancer. J Gastrointest Oncol 6: 185-200, 2015.

25. Suzuki K, Takaharu K, Muto Y, Ichida K, Fukui T, Takayama Y, Tsujinaka S, Sasaki J, Horie H, Kawamura YJ, et al: XELIRI regimen plus continuous treatment with bevacizumab is well-tolerated and effective in metastatic colorectal cancer patients in a second-line setting involving the sequential administration of XELOX and XELIRI. Mol Clin Oncol 2: 827-832, 2014.

26. Kawai S, Takeshima N, Hayasaka Y, Notsu A, Yamazaki M, Kawabata T, Yamazaki K, Mori K and Yasui H: Comparison of irinotecan and oxaliplatin as the first-line therapies for metastatic colorectal cancer: A meta-analysis. BMC Cancer 21: 116, 2021.

27. Marschner N, Arnold D, Engel E, Hutzschenreuter U, Rauh J, Freier W, Hartmann H, Frank $M$ and Jänicke $M$ : Oxaliplatin-based first-line chemotherapy is associated with improved overall survival compared to first-line treatment with irinotecan-based chemotherapy in patients with metastatic colorectal cancers-Results from a prospective cohort study. Clin Epidemiol 7: 295-303, 2015. 
28. Colucci G, Gebbia V, Paoletti G, Giuliani F, Caruso M, Gebbia N Cartenì G, Agostara B, Pezzella G, Manzione L, et al: Phase III randomized trial of FOLFIRI versus FOLFOX4 in the treatment of advanced colorectal cancer: A multicenter study of the Gruppo Oncologico Dell'Italia meridionale. J Clin Oncol 23: 4866-4875, 2005.

29. Aparicio T, Desramé J, Lecomte T, Mitry E, Belloc J, Etienney I, Montembault S, Vayre L, Locher C, Ezenfis J, et al: Oxaliplatin- or irinotecan-based chemotherapy for metastatic colorectal cancer in the elderly. Br J Cancer 89: 1439-1444, 2003.

30. André T, Afchain P, Barrier A, Blanchard P, Larsen AK, Tournigand C, Louvet $\mathrm{C}$ and de Gramont A: Current status of adjuvant therapy for colon cancer. Gastrointest Cancer Res 1: 90-97, 2007.

31. Patel K, Anthoney DA, Crellin AM, Sebag-Montefiore D, Messruther J and Seymour MT: Weekly 5-fluorouracil and leucovorin: Achieving lower toxicity with higher dose-intensity in adjuvant chemotherapy after colorectal cancer resection. Ann Oncol 15: 568-573, 2004

32. Schippinger W, Samonigg H, Schaberl-Moser R, Greil R, Thödtmann R, Tschmelitsch J, Jagoditsch M, Steger GG, Jakesz R, Herbst F, et al: A prospective randomised phase III trial of adjuvant chemotherapy with 5-fluorouracil and leucovorin in patients with stage II colon cancer. Br J Cancer 97: 1021-1027, 2007.

33. Fotheringham S, Mozolowski GA, Murray EMA and Kerr DJ: Challenges and solutions in patient treatment strategies for stage II colon cancer. Gastroenterol Rep (Oxf) 7: 151-161, 2019.

34. Twelves C, Wong A, Nowacki MP, Abt M, Burris H III, Carrato A, Cassidy J, Cervantes A, Fagerberg J, Georgoulias V, et al: Capecitabine as adjuvant treatment for stage III colon cancer. N Engl J Med 352: 2696-2704, 2005.

35. Cassidy J, Twelves C, Van Cutsem E, Hoff P, Bajetta E, Boyer M, Bugat R, Burger U, Garin A, Graeven U, et al: First-line ora capecitabine therapy in metastatic colorectal cancer: A favorable safety profile compared with intravenous 5-fluorouracil/leucovorin. Ann Oncol 13: 566-575, 2002.

36. Rizzo A, Nannini M, Astolfi A, Indio V, De Iaco P, Perrone AM, De Leo A, Incorvaia L, Di Scioscio V and Pantaleo MA: Impact of chemotherapy in the adjuvant setting of early stage uterine leiomyosarcoma: A systematic review and updated meta-analysis. Cancers (Basel) 12: 1899, 2020.

37. Rosales J and Leong LA: Chemotherapy for metastatic colorectal cancer. J Natl Compr Canc Netw 3: 525-529, 2005.

38. Mayer RJ, Van Cutsem E, Falcone A, Yoshino $T$, Garcia-Carbonero R, Mizunuma N, Yamazaki K, Shimada Y, Tabernero J, Komatsu Y, et al: Randomized trial of TAS-102 for refractory metastatic colorectal cancer. N Engl J Med 372: 1909-1919, 2015.

39. Grothey A, Van Cutsem E, Sobrero A, Siena S, Falcone A Ychou M, Humblet Y, Bouché O, Mineur L, Barone C, et al: Regorafenib monotherapy for previously treated metastatic colorectal cancer (CORRECT): An international, multicentre, randomised, placebo-controlled, phase 3 trial. Lancet 381: 303-312, 2013 .

40. Tonini G, Imperatori M, Vincenzi B, Frezza AM and Santini D: Rechallenge therapy and treatment holiday: Different strategies in management of metastatic colorectal cancer. J Exp Clin Cancer Res 32: 92, 2013

41. Bekaii-Saab T, Kim R, Kim TW, O'Connor JM, Strickler JH, Malka D, Sartore-Bianchi A, Bi F, Yamaguchi K, Yoshino T and Prager GW: Third- or Later-line therapy for metastatic colorectal cancer: Reviewing best practice. Clin Colorectal Cancer 18: e117-e129, 2019.

42. Kopetz S, Grothey A, Yaeger R, Van Cutsem E, Desai J, Yoshino T, Wasan H, Ciardiello F, Loupakis F, Hong YS, et al: Encorafenib, Binimetinib, and cetuximab in BRAF V600E-mutated colorectal cancer. N Engl J Med 381: 1632-1643, 2019.

43. Biller LH and Schrag D: Diagnosis and treatment of metastatic colorectal cancer: A review. JAMA 325: 669-685, 2021.

44. Overman MJ, McDermott R, Leach JL, Lonardi S, Lenz HJ, Morse MA, Desai J, Hill A, Axelson M, Moss RA, et al: Nivolumab in patients with metastatic DNA mismatch repair-deficient or microsatellite instability-high colorectal cancer (CheckMate 142): An open-label, multicentre, phase 2 study. Lancet Oncol 18: 1182-1191, 2017.

45. Smith KM and Desai J: Nivolumab for the treatment of colorectal cancer. Expert Rev Anticancer Ther 18: 611-618, 2018.
46. André T, Shiu KK, Kim TW, Jensen BV, Jensen LH, Punt C, Smith D, Garcia-Carbonero R, Benavides M, Gibbs P, et al: Pembrolizumab in microsatellite-instability-high advanced colorectal cancer. N Engl J Med 383: 2207-2218, 2020.

47. Overman MJ, Lonardi S, Wong KYM, Lenz HJ, Gelsomino F, Aglietta M, Morse MA, Van Cutsem E, McDermott R, Hill A, et al: Durable clinical benefit with nivolumab plus Ipilimumab in DNA mismatch Repair-Deficient/Microsatellite instability-high metastatic colorectal cancer. J Clin Oncol 36: 773-779, 2018.

48. Zheng Z, Yu T, Zhao X, Gao X, Zhao Y and Liu G: Intratumour heterogeneity: A new perspective on colorectal cancer research. Cancer Med 9: 7637-7645, 2020.

49. Losi L, Baisse B, Bouzourene H and Benhattar J: Evolution of intratumoural genetic heterogeneity during colorectal cancer progression. Carcinogenesis 26: 916-922, 2005

50. Molinari C, Marisi G, Passardi A, Matteucci L, De Maio G and Ulivi P: Heterogeneity in colorectal cancer: A challenge for personalized medicine? Int J Mol Sci 19: 3733, 2018

51. Buikhuisen JY, Torang A and Medema JP: Exploring and modelling colon cancer inter-tumour heterogeneity: Opportunities and challenges. Oncogenesis 9: 66, 2020.

52. Del Carmen S, Sayagués JM, Bengoechea O, Anduaga MF, Alcazar JA, Gervas R, García J, Orfao A, Bellvis LM, Sarasquete ME and Del Mar Abad M: Spatio-temporal tumour heterogeneity in metastatic CRC tumours: A mutational-based approach. Oncotarget 9: 34279-34288, 2018.

53. Blank A, Roberts DE II, Dawson H, Zlobec I and Lugli A: Tumour heterogeneity in primary colorectal cancer and corresponding metastases. Does the apple fall far from the tree? Front Med (Lausanne) 5: 234, 2018

54. Eide PW, Moosavi SH, Eilertsen IA, Brunsell TH, Langerud J, Berg KCG, Røsok BI, Bjørnbeth BA, Nesbakken A, Lothe RA and Sveen A: Metastatic heterogeneity of the consensus molecular subtypes of colorectal cancer. NPJ Genom Med 6: 59, 2021.

55. Hirata A, Hatano Y, Niwa M, Hara A and Tomita H: Heterogeneity of colon cancer stem cells. Adv Exp Med Biol 1139: 115-126, 2019.

56. Arakawa K, Hata K, Nozawa H, Kawai K, Tanaka T, Nishikawa T, Sasaki K, Shuno Y, Kaneko M, Hiyoshi M, et al: Molecular subtypes are frequently discordant between lesions in patients with synchronous colorectal cancer: Molecular analysis of 59 patients. Anticancer Res 39: 1425-1432, 2019.

57. Li ZN, Zhao L, Yu LF and Wei MJ: BRAF and KRAS mutations in metastatic colorectal cancer: Future perspectives for personalized therapy. Gastroenterol Rep (Oxf) 8: 192-205, 2020.

58. Christensen TD, Palsh of JA, Larsen FO, Poulsen TS, Høgdall E, Pfeiffer P, Jensen BV, Yilmaz MK and Nielsen D: Associations between primary tumour RAS, BRAF and PIK3CA mutation status and metastatic site in patients with chemo-resistant metastatic colorectal cancer. Acta Oncol 57: 1057-1062, 2018.

59. Fedyanin M, Stroganova A, Senderovich A, Dranko S, Tryakin A, Polyanskaya E, Popova A, Sekhina O, Rasulov A, Gordeev S, et al: Factors associated with discordance of KRAS, NRAS, BRAF, PIK3CA mutation status in the primary tumour and metastases in patients (pts) with colorectal cancer (CRC). Annals Oncol 27 (Suppl 6): VI174, 2016.

60. Watanabe T, Kobunai T, Yamamoto Y, Matsuda K, Ishihara S, Nozawa K, Iinuma H, Shibuya $\mathrm{H}$ and Eshima K: Heterogeneity of KRAS status may explain the subset of discordant KRAS status between primary and metastatic colorectal cancer. Dis Colon Rectum 54: 1170-1178, 2011

61. Siyar Ekinci A, Demirci U, Cakmak Oksuzoglu B, Ozturk A, Esbah O, Ozatli T, Celik B, Budakoglu B, Turker I, Bal O and Turan N: KRAS discordance between primary and metastatic tumour in patients with metastatic colorectal carcinoma. J BUON 20: 128-135, 2015

62. Ardito F, Razionale F, Salvatore L, Cenci T, Vellone M, Basso M, Panettieri E, Calegari MA, Tortora G, Martini M and Giuliante F: Discordance of KRAS mutational status between primary tumours and liver metastases in colorectal cancer: Impact on long-term survival following radical resection. Cancers (Basel) 13: 2148, 2021.

63. Estrella JS, Tetzlaff MT, Bassett RL Jr, Patel KP, Williams MD, Curry JL, Rashid A, Hamilton SR and Broaddus RR: Assessment of BRAF V600E status in colorectal carcinoma: Tissue-specific discordances between immunohistochemistry and sequencing. Mol Cancer Ther 14: 2887-2895, 2015. 
64. Mas L, Bachet JB, Taly V, Bouché O, Taieb J, Cohen R, Meurisse A, Normand C, Gornet JM, Artru P, et al: BRAF mutation status in circulating tumour DNA from patients with metastatic colorectal cancer: Extended mutation analysis from the AGEO RASANC study. Cancers (Basel) 11: 998, 2019.

65. Bai H, Wang R, Cheng W, Shen Y, Li H, Xia W, Ding Z and Zhang Y: Evaluation of concordance between deficient mismatch repair and microsatellite instability testing and their association with clinicopathological features in colorectal cancer. Cancer Manag Res 12: 2863-2873, 2020.

66. Haraldsdottir S, Roth R, Pearlman R, Hampel H, Arnold CA and Frankel WL: Mismatch repair deficiency concordance between primary colorectal cancer and corresponding metastasis. Fam Cancer 15: 253-260, 2016.

67. Vyas M, Firat C, Hechtman JF, Weiser MR, Yaeger R, Vanderbilt C, Benhamida JK, Keshinro A, Zhang L, Ntiamoah $\mathrm{P}$, et al: Discordant DNA mismatch repair protein status between synchronous or metachronous gastrointestinal carcinomas: Frequency, patterns, and molecular etiologies. Fam Cancer 20: 201-213, 2021

68. Yaeger R: Heterogeneity in microsatellite instability in metastatic colorectal cancer: Mechanisms and clinical implications. J Natl Compr Canc Netw 17: 1263-1264, 2019.

69. De Smedt L, Lemahieu J, Palmans S, Govaere O, Tousseyn T, Van Cutsem E, Prenen H, Tejpar S, Spaepen M, Matthijs G, et al Microsatellite instable vs stable colon carcinomas: Analysis of tumour heterogeneity, inflammation and angiogenesis. $\mathrm{Br}$ J Cancer 113: 500-509, 2015.

70. Levin-Sparenberg E, Bylsma LC, Lowe K, Sangare L, Fryzek JP and Alexander DD: A systematic literature review and meta-analysis describing the prevalence of KRAS, NRAS, and BRAF Gene mutations in metastatic colorectal cancer. Gastroenterology Res 13: 184-198, 2020.

71. Hu Y, Tao SY, Deng JM, Hou ZK, Liang JQ, Huang QG, Li LH, $\mathrm{Li} \mathrm{HB}$, Chen YM, Yi H, et al: Prognostic value of NRAS gene for survival of colorectal cancer patients: A systematic review and meta-analysis. Asian Pac J Cancer Prev 19: 3001-3008, 2018.

72. Wang J, Shen J, Huang C, Cao M and Shen L: Clinicopathological significance of $\mathrm{BRAF}^{\mathrm{V} 600 \mathrm{E}}$ mutation in colorectal cancer: An updated meta-analysis. J Cancer 10: 2332-2341, 2019.

73. Wensink E, Bond M, Kucukkose E, May A, Vink G, Koopman M, Kranenburg $\mathrm{O}$ and Roodhart J: A review of the sensitivity of metastatic colorectal cancer patients with deficient mismatch repair to standard-of-care chemotherapy and monoclonal antibodies, with recommendations for future research. Cancer Treat Rev 95: 102174, 2021.

74. Wheeler JM, Bodmer WF and Mortensen NJ: DNA mismatch repair genes and colorectal cancer. Gut 47: 148-153, 2000

75. Hou JT, Zhao LN, Zhang DJ, Lv DY, He WL, Chen B, Li HB Li PR, Chen LZ and Chen XL: Prognostic value of mismatch repair genes for patients with colorectal cancer: Meta-analysis Technol Cancer Res Treat 17: 1533033818808507, 2018.

76. Kang S, Na Y, Joung SY, Lee SI, Oh SC and Min BW: The significance of microsatellite instability in colorectal cancer after controlling for clinicopathological factors. Medicine (Baltimore) 97: e0019, 2018.

77. Nojadeh JN, Behrouz Sharif S and Sakhinia E: Microsatellite instability in colorectal cancer. EXCLI J 17: 159-168, 2018.

78. Anele CC, Adegbola SO, Askari A, Rajendran A, Clark SK, Latchford A and Faiz OD: Risk of metachronous colorectal cancer following colectomy in Lynch syndrome: A systematic review and meta-analysis. Colorectal Dis 19: 528-536, 2017.

79. Duraturo F, Liccardo R, De Rosa M and Izzo P: Genetics, diagnosis and treatment of Lynch syndrome: Old lessons and current challenges. Oncol Lett 17: 3048-3054, 2019.

80. Boland CR and Goel A: Microsatellite instability in colorectal cancer. Gastroenterology 138: 2073-2087.e3, 2010.

81. Morelli MP, Overman MJ, Dasari A, Kazmi SMA, Mazard T, Vilar E, Morris VK, Lee MS, Herron D, Eng C, et al: Characterizing the patterns of clonal selection in circulating tumour DNA from patients with colorectal cancer refractory to anti-EGFR treatment. Ann Oncol 26: 731-736, 2015.

82. Van Emburgh BO, Sartore-Bianchi A, Di Nicolantonio F, Siena S and Bardelli A: Acquired resistance to EGFR-targeted therapies in colorectal cancer. Mol Oncol 8: 1084-1094, 2014.

83. Yachida S, Jones S, Bozic I, Antal T, Leary R, Fu B, Kamiyama M, Hruban RH, Eshleman JR, Nowak MA, et al: Distant metastasis occurs late during the genetic evolution of pancreatic cancer. Nature 467: 1114-1117, 2010.
84. Ricci-Vitiani L, Lombardi DG, Pilozzi E, Biffoni M, Todaro M, Peschle $C$ and De Maria R: Identification and expansion of human colon-cancer-initiating cells. Nature 445: 111-115, 2007.

85. Sottoriva A, Kang H, Ma Z, Graham TA, Salomon MP, Zhao J, Marjoram P, Siegmund K, Press MF, Shibata D and Curtis C: A Big Bang model of human colorectal tumour growth. Nat Genet 47: 209-216, 2015 .

86. Fujiyoshi K, Yamamoto G, Takahashi A, Arai Y, Yamada M, Kakuta M, Yamaguchi K, Akagi Y, Nishimura Y, Sakamoto H and Akagi K: High concordance rate of KRAS/BRAF mutations and MSI-H between primary colorectal cancer and corresponding metastases. Oncol Rep 37: 785-792, 2017.

87. Bhullar DS, Barriuso J, Mullamitha S, Saunders MP O'Dwyer ST and Aziz O: Biomarker concordance between primary colorectal cancer and its metastases. EBioMedicine 40: 363-374, 2019

88. Ruiz-Bañobre J, Kandimalla R and Goel A: Predictive biomarkers in metastatic colorectal cancer: A systematic review. JCO Precis Oncol 3: PO.18.00260, 2019.

89. Zou Y, Hu X, Zheng S, Yang A, Li X, Tang H, Kong Y and Xie X: Discordance of immunotherapy response predictive biomarkers between primary lesions and paired metastases in tumours: A systematic review and meta-analysis. EBioMedicine 63: 103137, 2021.

90.Zou SM, Li WH, Wang WM, Li WB, Shi SS, Ying JM and Lyu N: The gene mutational discrepancies between primary and paired metastatic colorectal carcinoma detected by next-generation sequencing. J Cancer Res Clin Oncol 144: 2149-2159, 2018.

91. Guyot D'Asnières De Salins A, Tachon G, Cohen R, Karayan-Tapon L, Junca A, Frouin E, Godet J, Evrard C, Randrian V, Duval A, et al: Discordance between immunochemistry of mismatch repair proteins and molecular testing of microsatellite instability in colorectal cancer. ESMO Open 6 : 100120, 2021

92. Mao C, Wu XY, Yang ZY, Threapleton DE, Yuan JQ, Yu YY and Tang JL: Concordant analysis of KRAS, BRAF, PIK3CA mutations, and PTEN expression between primary colorectal cancer and matched metastases. Sci Rep 5: 8065, 2015.

93. Kim KP, Kim JE, Hong YS, Ahn SM, Chun SM, Hong SM, Jang SJ, Yu CS, Kim JC and Kim TW: Paired primary and metastatic tumour analysis of somatic mutations in synchronous and metachronous colorectal cancer. Cancer Res Treat 49: 161-167, 2017.

94. Jesinghaus M, Wolf T, Pfarr N, Muckenhuber A, Ahadova A, Warth A, Goeppert B, Sers C, Kloor M, Endris V, et al: Distinctive spatiotemporal stability of somatic mutations in metastasized microsatellite-stable colorectal Cancer. Am J Surg Pathol 39: 1140-1147, 2015

95. Lee CC, Soon YY, Lum JHY, Tan CL and Tey JCS: Frequency of discordance in programmed death-ligand 1 (PD-L1) expression between primary tumours and paired distant metastases in advanced cancers: A systematic review and meta-analysis. Acta Oncol 59: 696-704, 2020

96. Gerlinger M, Rowan AJ, Horswell S, Math M, Larkin J, Endesfelder D, Gronroos E, Martinez P, Matthews N, Stewart A, et al: Intratumour heterogeneity and branched evolution revealed by multiregion sequencing. N Engl J Med 366: 883-892, 2012

97. Molinari F, Martin V, Saletti P, De Dosso S, Spitale A, Camponovo A, Bordoni A, Crippa S, Mazzucchelli L and Frattini M: Differing deregulation of EGFR and downstream proteins in primary colorectal cancer and related metastatic sites may be clinically relevant. Br J Cancer 100: 1087-1094, 2009.

98. He Q, Xu Q, Wu W, Chen L, Sun W and Ying J: Comparison of KRAS and PIK3CA gene status between primary tumours and paired metastases in colorectal cancer. Onco Targets Ther 9: 2329-2335, 2016.

99. Niitsu H, Hinoi T, Shimomura M, Egi H, Hattori M, Ishizaki Y, Adachi T, Saito Y, Miguchi M, Sawada H, et al: Up-front systemic chemotherapy is a feasible option compared to primary tumour resection followed by chemotherapy for colorectal cancer with unresectable synchronous metastases. World J Surg Oncol 13: 162, 2015.

100. Giacchetti S, Itzhaki M, Gruia G, Adam R, Zidani R, Kunstlinger F, Brienza S, Alafaci E, Bertheault-Cvitkovic F, Jasmin C, et al: Long-term survival of patients with unresectable colorectal cancer liver metastases following infusional chemotherapy with 5-fluorouracil, leucovorin, oxaliplatin and surgery. Ann Oncol 10: 663-669, 1999. 
101. Stillwell AP, Buettner PG and Ho YH: Meta-analysis of survival of patients with stage IV colorectal cancer managed with surgical resection versus chemotherapy alone. World J Surg 34: 797-807, 2010.

102. Wang G, Wang W, Jin H, Dong H, Chen W, Li X, Li G and Li L: The effect of primary tumour radiotherapy in patients with Unresectable stage IV rectal or Rectosigmoid cancer: A propensity score matching analysis for survival. Radiat Oncol 15: 126, 2020.

103. Poultsides GA and Paty PB: Reassessing the need for primary tumour surgery in unresectable metastatic colorectal cancer: Overview and perspective. Ther Adv Med Oncol 3: 35-42, 2011.

104. Park JH, Kim TY, Lee KH, Han SW, Oh DY, Im SA, Kang GH, Chie EK, Ha SW, Jeong SY, et al: The beneficial effect of palliative resection in metastatic colorectal cancer. Br J Cancer 108 : 1425-1431, 2013.

105. Simillis C, Kalakouti E, Afxentiou T, Kontovounisios C, Smith JJ, Cunningham D, Adamina M and Tekkis PP: Tumour resection in patients with incurable localized or metastatic colorectal cancer: A systematic review and meta-analysis. World J Surg 43: 1829-1840, 2019.

106. Feo L, Polcino M and Nash GM: Resection of the primary tumour in stage IV colorectal cancer: When is it necessary? Surg Clin North Am 97: 657-669, 2017.

107. www.beaumont.ie/media/Testing_Services_Offered1.pdf

108. Radiology Assistant: RECIST 1.1-and more. Response Evaluation Criteria In Solid Tumors. https://radiologyassistant. nl/more/recist-1-1/recist-1-1. Accessed December 7, 2021.

109. Cutsem EV, Cervantes A, Nordlinger B and Arnold D; ESMO Guidelines Working Group: Metastatic colorectal cancer: ESMO clinical practice guidelines for diagnosis, treatment and follow-up. Ann Oncol 25 (Suppl 3): iiil-iii9, 2014.

110. Chiorean EG, Nandakumar G, Fadelu T, Temin S, Alarcon-Rozas AE, Bejarano S, Croitoru AE, Grover S, Lohar PV, Odhiambo A, et al: Treatment of patients with late-stage colorectal cancer: ASCO Resource-stratified guideline. JCO Glob Oncol 6: 414-438, 2020.

111. Muratore A, Zorzi D, Bouzari H, Amisano M, Massucco P, Sperti E and Capussotti L: Asymptomatic colorectal cancer with Un-Resectable liver metastases: Immediate colorectal resection or up-front systemic chemotherapy? Ann Surg Oncol 14: 766-770, 2007.
112. Pedziwiatr M, Mizera M, Witowski J, Major P, Torbicz G, Gajewska $\mathrm{N}$ and Budzyński A: Primary tumour resection in stage IV unresectable colorectal cancer: What has changed? Med Oncol 34: 188, 2017.

113. Poultsides GA, Servais EL, Saltz LB, Patil S, Kemeny NE, Guillem JG, Weiser M, Temple LK, Wong WD and Paty PB: Outcome of primary tumour in patients with synchronous stage IV colorectal cancer receiving combination chemotherapy without surgery as initial treatment. J Clin Oncol 27: 3379-3384, 2009

114. Seo GJ, Park JW, Yoo SB, Kim SY, Choi HS, Chang HJ, Shin A, Jeong SY, Kim DY and Oh JH: Intestinal complications after palliative treatment for asymptomatic patients with unresectable stage IV colorectal cancer. J Surg Oncol 102: 94-99, 2010.

115. Rahbari NN, Lordick F, Fink C, Bork U, Stange A, Jäger D, Luntz SP, Englert S, Rossion I, Koch M, et al: Resection of the primary tumour versus no resection prior to systemic therapy in patients with colon cancer and synchronous unresectable metastases (UICC stage IV): SYNCHRONOUS-a randomised controlled multicentre trial (ISRCTN30964555). BMC Cancer 12: 142, 2012

116. Moritani K, Kanemitsu Y, Shida D, Shitara K, Mizusawa J, Katayama H, Hamaguchi T and Shimada Y; Colorectal Cancer Study Group (CCSG) of Japan Clinical Oncology Group (JCOG): A randomized controlled trial comparing primary tumour resection plus chemotherapy with chemotherapy alone in incurable stage IV colorectal cancer: JCOG1007 (iPACS study). Jpn J Clin Oncol 50: 89-93, 2020.

117. Van Cutsem E, Cervantes A, Adam R, Sobrero A, Van Krieken JH, Aderka D, Aranda Aguilar E, Bardelli A, Benson A, Bodoky G, et al: ESMO consensus guidelines for the management of patients with metastatic colorectal cancer. Ann Oncol 27: 1386-1422, 2016.

This work is licensed under a Creative Commons Attribution-NonCommercial-NoDerivatives 4.0 International (CC BY-NC-ND 4.0) License. 